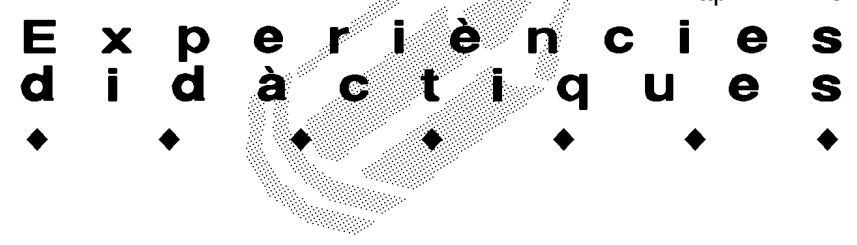

\title{
PER UN APROFITAMENT CONSEQÜENT DEL MEDI: EL LLIGAM ROMA-TÀRRACO
}

\begin{abstract}
Antoni Gavaldà Torrents. Didàctica de les Ciències Socials. URV. M. Joana Virgili Gasol. Camp d'Aprenentatge Ciutat de Tarragona
\end{abstract}

\section{Tarragona, ciutat romana}

Roma és present a Tarragona i als seus voltants en manifestacions visibles o induïdes, passats més de dos mil-lenis des del seu assentament, ocupació i posterior integració. Els vestigis de l'època que es conserven avui en dia són importants en quantitat i qualitat, i inunden la ciutat i els voltants. És conegut que el pas de Roma per Tarragona va influir decisivament en la configuració constructiva de la ciutat, ordenant i ocupant un espai en terrasses adaptat a un terreny aturonat. Si Tàrraco va esdevenir la ciutat pont entre Roma, no menys important va ser el teixit poblacional que s'assentà pels voltants, en forma de vil.les, aprofitant les zones agràries més productives i desenvolupant una tasca agrícola de primer ordre.

El potencial de vestigis vius de Tàrraco a Tarragona i a l'entorn per endinsar-se en l'entramat social i cultural resulta extraordinari, i òbviament es pot abordar de moltes maneres i actituds, amb alumnes de diferents edats. Un possible exemple d'actuació ens el dóna partir del mateix plànol de la ciutat romana, en contrast amb l'actual, que permetria constatar el que significà l'assentament d'una població estable i les seves necessitats. Aquesta opció concreta facilitaria treballar, entre altres, de forma gradual, qüestions com les següents:

- El model de xarxa urbana que feren servir els romans per a aquesta ciutat específica.

- Les solucions constructives que es donaren als terrenys, en terrassa.

- La forma d'alineació dels carrers per construir-hi les cases.

- El domini de l'espai dels edificis públics de gestió i de poder.

- L'opció que donaren al port, integrat en la trama urbana.

- Les solucions d'espais arbitrades a la construcció d'edificis lúdics i la incorporació de nous espais, dins i fora de la ciutat, per hostatjar-ne.

- La construcció de serveis bàsics centrats en l'aigua i el clavegueram.

- La solució donada a la defensa de la ciutat, emmurallada, amb portes d'entrada i sortida.
- La xarxa de compra-venda de productes al mercat local.

- La necessitat de construcció de camins, calçades i ponts per afavorir l'intercanvi i la relació.

- El requisit de poder disposar de bones pedreres a zones properes per bastir de matèria primera l'entramat constructiu.

- La possibilitat de captar la diferenciació dels treballs de les persones a partir de vestigis conservats.

- La solució que es donà a l'enterrament dels ciutadans.

- La fixació de vil.les romanes com a nucli d'agrupació econòmica i social.

- El tractament que es donà per honorar els déus i els emperadors: vestigis visibles i induïts.

Tanmateix, aquests aspectes no serien pas els únics que es podrien treballar al voltant del plànol i de la situació d'espais. La ciutat de Tarragona i la zona aporten altres detalls introspectius de la vida de les persones i dels treballs que realitzaven, aconseguits a partir de troballes i d'estudis sectorials, que podrien ser objecte d'estudi i reflexió. Alguns dels quals, també com a exemple, podrien ser:

- La concreció de com seria el dia a dia de les persones: determinar com s'estructurava el dia en funció de si la persona era ciutadà o esclau, intentant captar com la naixença ja prefigurava un determinat estatus social.

- Resseguir la vida dels infants i nois: a través de la forma d'educar i instruir des de la família i l'escola, els jocs i els seus utensilis, la iniciació al treball.

- La perspectiva de com era un determinat ofici: intentar visionar-lo, captar-ne les rutines.

- La vida quotidiana en la faceta de mercat: compradors, venedors, intercanvi, bescanvi, l'ús de les monedes.

- La percepció de les relacions socials: comprensió de les relacions familiars, l'assistència a llocs de culte i d'esbarjo, el ritus del pas a l'edat adulta.

- El component dedicat a les sensacions: serviria per a precisar les vivències en situacions com els canvis i les continuïtats de com eren els casa- 


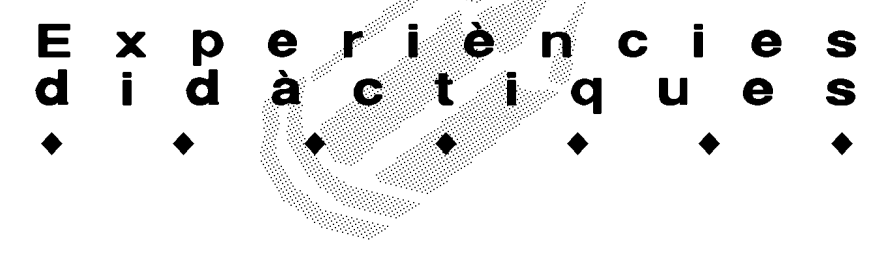

ments, els naixements, la mateixa mort, etc.

- La manera de presentar-se davant dels altres: hi entraria des de la peculiaritat del vestit, el calçat, la cura personal del pentinat, els perfums, els penjolls...

Per treballar-los amb alumnes, caldria extreure aquests components a partir de plans preparats: evidentment a través de textos de l'època, però també a partir de preguntes escaients als vestigis; a través de l'ajut d'elements de la museística, o fins i tot en un pla de recreació simbòlica. Entre els vestigis materials de ciutat, Tarragona disposa de cases, amb mosaics i clavegueres, de mercat o fòrum, de termes, de temples, de l'amfiteatre, del circ, de l'aqüeducte..., i entre els de fora són visibles l'arc de triomf, les calçades, els cementiris individuals i col-lectius, les vil.les agrícoles, etc. Pel que fa als museus, hi entrarien des d'elements d'ostentació i recreació com les estàtues i els mosaics, o objectes de vida quotidiana com els estris casolans del dia a dia i els jocs, fins a peces de defunció com els sarcòfags, per posar-ne uns exemples. Quant a la recreació simbòlica, en parlarem en un punt específic més endavant.

\section{Bases per treballar Roma i Tàrraco amb escolars}

La comprensió de la petjada material i patrimonial d'una zona i de les persones que la modelaren per les seves necessitats és una tasca que la ciència històrica procura descabdellar amb garanties, amb l'ajut de ciències auxiliars com l'arqueologia, la numismàtica, la paleografia, etc. És, però, la didàctica de la disciplina social la ciència que ajuda a aplanar el saber i la referida vivència, la que procura fer-la digerible per als escolars. L'intent d'apropar la realitat de l'ahir a l'avui per entendre els significats clau del període sempre ha existit. Aquest apropament es realitza a través d'unes pautes de transmissió cultural, des de la via escolar o bé a través de programes per a un públic abocat a un oci cultural. Serà en la primera faceta en la que ens mourem, a través de la didàctica de les ciències socials, buscant fórmules actives, per procurar que la comprensió escolar esdevingui el més eficient possible, partint de la base que l'alumne activi i mostri un interès a voler aprendre. Conseqüentment amb el que acabem d'assenyalar, i en el cas que ens ocupa de Roma i Tarragona, partim de l'actuació del Camp d'Aprenentatge de Tarragona -com a model català d'immersió actiu impulsat pel Departament d'Educació de la Generalitat, que permet capbussar-se sobre Roma a les escoles que hi participen- com a organisme encarregat de preparar un menú educatiu per aconseguir un aprenentatge eficient.

La simbiosi entre didàctica i camp d'aprenentatge, en format de vasos comunicants, ha de permetre re- construir la vivència d'un període d'ampli abast cronològic -p. e. l'estada de Roma a Tàrraco-, a fi i efecte que els alumnes l'entenguin en clau d'ahir i d'avui, i que en quedin amarats, a partir de les relacions del passat amb el present, i sobretot que sàpiguen indagar el passat per projectar-lo al futur. Per a una adequada projecció educativa caldria contextualitzar el període en un sentit sociocultural ampli que permetés un treball diversificat, per ajudar a bastir la comprensió d'un entramat polític, social, cultural i patrimonial. El radi d'acció es presentaria per a totes les edats.

El predicament de poder transitar per múltiples vies, en funció del que es busqui aconseguir -algunes de les quals, succintament, apuntarem-, hauria de permetre poder sectoritzar el coneixement cap a on es busqui incidir. Comptat i debatut, les bases de treball conceptuals o aplicades per a l'estudi de Tàrraco que s'han tingut $i$ es tindran presents en aquest planteig passarien per eixos connectors com:

- Perquè l'aprenentatge de la història no és privatiu només de ser treballat en certes edats. Hi ha models d'altres latituds que determinen que la història pot entrar des de les etapes de l'educació infantil.

- Perquè si el treball i el joc són compatibles en el terreny dels aprenentatges informals, també ho han de ser a la programació escolar. Això ajudaria a ampliar els interessos a fets més remots, i la interrelació seria un bon eix per comprendre la història, la geografia o les ciències físiconaturals.

- Perquè entenem la història com a integrada en la mateixa vivència social, i per tant no pot separarse de la resta de les ciències socials. Un problema social o polític dista molt de presentar-se nítid, immaculat. Les causes que l'han propiciat i les conseqüències que se'n deriven van més enllà d'un simple avatar històric. La confluència de factors implica que es produeixi relació, i en aquesta no podem ni hem de separar aspectes socials concatenats d'història i sociologia, d'història i economia, d'història i art...

- Perquè si bé és provat que el raonament històric busca el sentit i les respostes que ha donat l'home a la vida en moments concrets, no és menys cert que el raonament agafa un sentit més sòlid en períodes cronològics llargs, en cicles d'avenços i retrocessos, en moments de pauses i crisis, quan emergeixen els canvis i les continuïtats.

- Perquè, tot i que la història té diverses vies per on es pot abordar, convenim que fins fa poc s'ha descuidat el patrimoni historicoartístic en el seu sentit més social, de patrimoni cultural. Així, la faceta del patrimoni historicoartístic, arquitectònic, mo- 


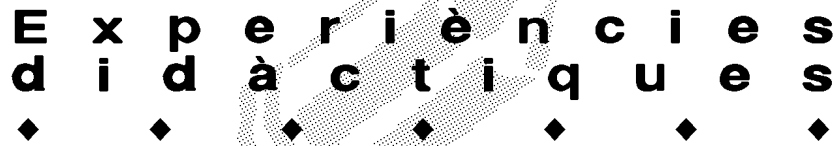

numental o arqueològic, sovint se l'ha vist només com a eix complementari, descuidant un valor educatiu de present i de futur, aspectes en els quals es vol incidir.

- Perquè si en tota explicació històrica apareix un component globalitzador, no volem descuidar el vessant polític, l'econòmic, el científicotècnic, l'ideològic i el cultural. Això fa que vulguem treballar amb els alumnes a partir d'una explicació i raonament de fets del passat, integrada en un ampli context cultural, com a marc d'una època.

- Perquè l'estudi de Tàrraco i voltants permet preparar un treball diversificat d'assentament urbà, en eixos conceptuals i procedimentals. Es pot tractar des de conceptes de trama urbana fins a l'anàlisi de la ciutat basada en l'observació i recollida de dades o el processament d'informació urbana, entre altres de possibles.

- Perquè les ciències socials han d'aprofitar el testimoni històric que proporcionen les restes de què es disposa, a partir d'un marc contextual. Si el treball amb història és saber plantejar preguntes -i intentar respondre-les-, l'estudi d'un fet, d'un període o fins d'una civilització passa per estimular a preguntar-se amb la base de documents o amb vestigis.

En definitiva, si aquestes són algunes de les causes per les quals Roma i Tàrraco poden entrar amb ímpetu a l'escola, vegem tot seguit realitats tangibles sobre el terreny.

\section{Les propostes didàctiques de com treballar Tàrraco amb escolars. Materials i finalitats}

La ciutat de Tarragona, ho hem dit, ofereix moltes possibilitats de treball des de diversos angles. Volem recordar que les ciutats han jugat de sempre un paper de primer ordre en les influències culturals de les persones. Pèricles afirmà que "Atenes és en tot l'escola de Grècia". I tot i que les ciutats són complexes, fruit de molts condicionants, hereves d'una llarga història i d'uns processos culturals, són també un vehicle idoni perquè els escolars entrin en contacte amb la realitat immediata, i coneguin i comprenguin l'entorn físic, econòmic, social i històric

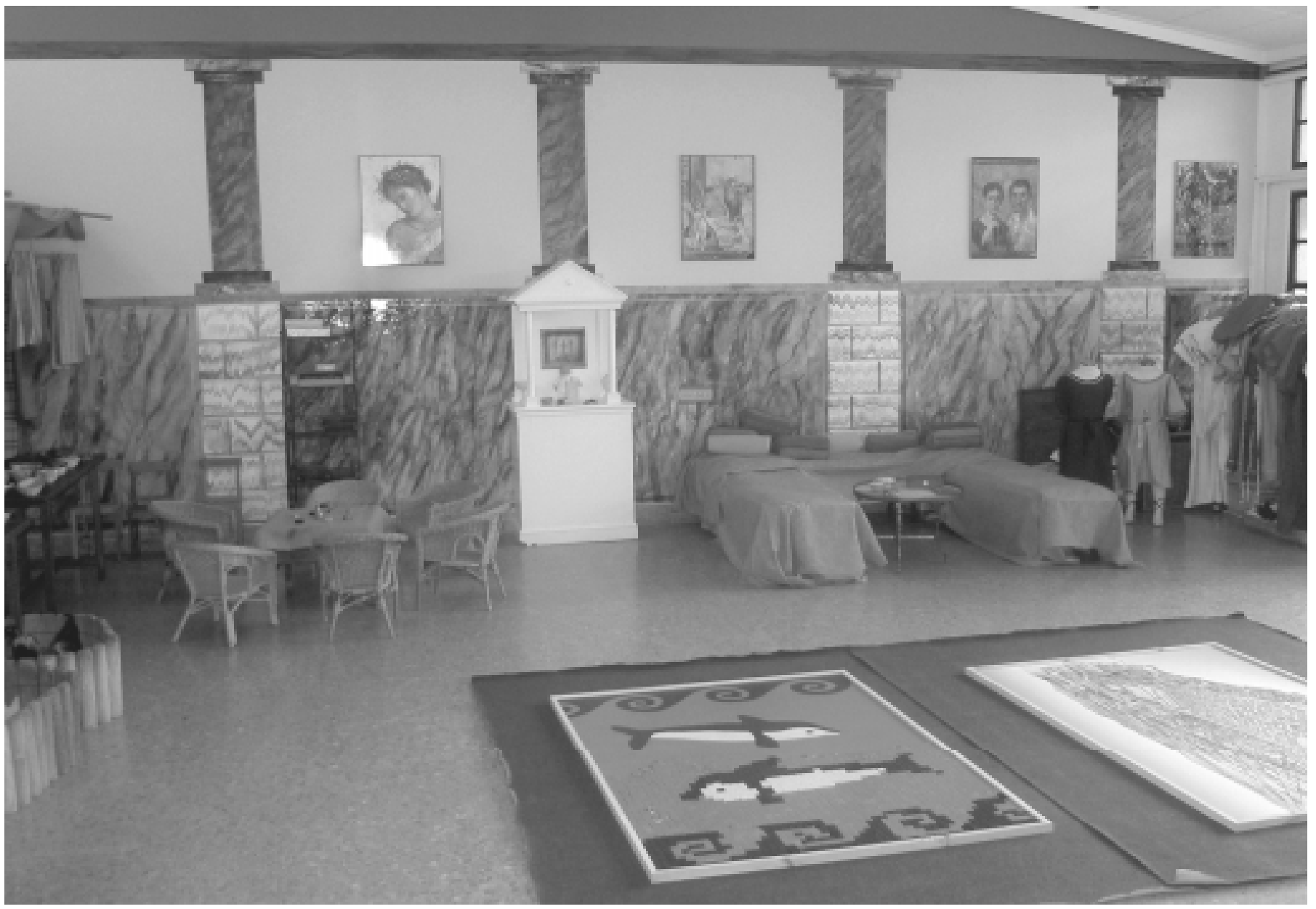




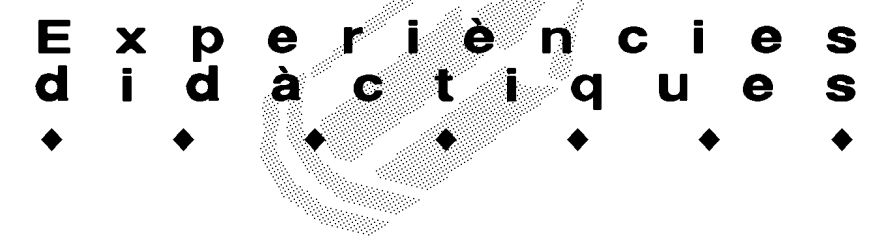

de l'indret on viuen o que visiten.

L'antiga Tàrraco, avui Tarragona, és una ciutat rica en recursos per treballar, plena d'història que encara es viu als carrers i places o bé se serva als museus. La riquesa i la diversitat de realitats del passat que es troben a Tarragona justifiquen mirades transversals. Paisatge privilegiat a la vora del mar, l'escriptor Lucius Anneus Florus la definí com Tarraco civitas ubi ver aeternum est, és a dir, com "la ciutat on la primavera és eterna". Aquests trets del medi natural poden arribar a explicar, almenys en part, la barreja de grups socials que hi han viscut, tot i que els romans serien els que hi deixarien una empremta més visible.

Estem, doncs, convençuts de la importància de Tarragona com a recurs didàctic de primer ordre, tal com també va entendre l'administració educativa catalana, que va crear un servei propi, un camp d'aprenentatge. Aquest ha ajudat a traspassar el saber del món acadèmic al món escolar i ha possibilitat la relació dels alumnes amb vestigis, en l'aprenentatge des de la ciutat romana. El Camp d'Aprenentatge de Tarragona com a servei educatiu del Departament d'Educació de la Generalitat de Catalunya, gestionat per professionals de l'ensenyament, ofereix a tots els centres de Catalunya -i als de fora que ho demanen- diferents propostes didàctiques centrades en l'estudi d'àmbits de la ciutat, un eix dels quals el configura la Tarragona dels romans. Des del Camp, els objectius d'aprenentatge encarats als alumnes, al mateix professorat i als centres educatius, són:

- Dotar els alumnes d'instruments atractius per a un millor coneixement de l'entorn.

- Formar els professors i els estudiants de Mestre que es dedicaran a l'ensenyament en noves metodologies, especialment dirigides al treball de camp.

- Ajudar a dissenyar seqüències didàctiques que desenvolupin el currículum escolar en el tema que es treballi.

- Elaborar projectes didàctics conjunts que involucrin els centres educatius de l'entorn.

Aquests eixos constituiran una font de retroalimentació didàctica dels agents implicats en benefici dels alumnes.

En conseqüència amb el que s'acaba d'indicar, des del Camp d'Aprenentatge s'intentarà aplicar una metodologia participativa de base manipulativa, implicant l'alumne perquè sigui el protagonista de l'aprenentatge i perquè alhora sigui el saber, conjunt a la seva pròpia experiència, qui el porti a descobrir, per ell mateix, les característiques de les restes de la ciutat romana, i tot allò que nosaltres, com a docents, directament $\mathrm{o}$ indirecta, li proposarem. Per aconseguir-ho es dissenyen unes activitats diversificades des de molts flancs, variades, obertes, motivadores, divertides, dinàmiques, sorprenents (algunes amb un punt d'intriga, de misteri, d'aventura, reflexives, recapituladores, etc.). La sorpresa a què fem esment l'entenem com a punt de partida per realitzar algunes de les activitats -les anomenem punt 0 -, perquè aquest voler saber es converteixi en una constant del comprendre i investigar.

A la metodologia la segueixen els recursos. Els recursos específics que ofereix la ciutat passen per diversos indrets. La localització i identificació de les restes romanes de la ciutat i dels voltants són, com hem insinuat, múltiples: les muralles, l'amfiteatre, el pretori, el circ, la necròpolis, l'aqüeducte, la pedrera del Mèdol, la torre dels Escipions, l'arc de Berà, el fòrum local i el carrer, les vil.les de Centcelles i dels Munts, a més del Museu Nacional Arqueològic. Aquesta profusió de recursos permeten realitzar treballs variats:

- Identificar els trets bàsics d'aspectes de la història i cultura del món romà.

- Reconèixer les característiques que configuraren els espais bàsics d'una ciutat romana, així com dels edificis més emblemàtics del moment.

- Contextualitzar la ciutat antiga comparativament amb l'actual.

- Saber relacionar els trets bàsics de les formes de vida a l'època romana.

- Reconèixer aspectes del món romà que formen part de la nostra cultura, com els jocs, la llengua, els aliments, el dret...

Des d'aquest plantejament, descobrir, comprendre i interpretar el funcionament i l'organització del sistema urbà, a l'època romana, a partir de Tarragona, constitueix una finalitat educativa que volem que proporcioni claus adequades per desxifrar la ciutat d'aquell moment. Un cop resolta aquesta finalitat, podrem visualitzar les comparacions que s'escaiguin i ens "podrem traslladar" a altres ciutats. En aquesta comesa de comprensió hi té a veure el Camp d'Aprenentatge, ja que és el que perfila uns eixos de treball en un seguit d'activitats, preparades en cinc blocs: per al cicle inicial de primària (CIP), per al cicle superior de primària (CSP), per a la primària com a conjunt (EP), per a l'educació secundària obligatòria (ESO) i per al batxillerat (BAT).

D'acord amb el que s'ha indicat, aquest és el treball que s'ofereix a les escoles, i en definitiva als alumnes que hi participen, a partir de quatre grans blocs, en 33 variables possibles distribuïdes entre els cicles i les etapes de què hi ha material preparat:

Els monuments (en 20 variables):

- El circ, L'amfiteatre i L'aqüeducte (hi ha materials adequats per treballar a EP, ESO i BAT), El pretori 


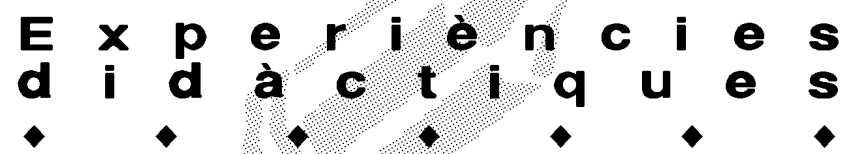

(CSP, ESO i BAT), El fòrum local (CSP i ESO), La muralla (EP i ESO), i El Mèdol i La torre dels Escipions (ESO i BAT).

La vida quotidiana (en 9 variables):

- Els petits nens i nenes de la Tàrraco romana $(\mathrm{Cl})$, Juguem com jugaven les nenes $i$ els nens de Tàrraco (CSP), El legionari i De l'ou a la poma (ESO), Roma a la moda (EP i ESO), La medicina romana (BAT), La higiene i l'estètica (ESO i BAT).

L'urbanisme (en 3 variables):

- Tàrraco, la ciutat romana (CSP), Tàrraco, la ciutat romana. Crèdit per a secundària (ESO) i La vil.la romana dels Munts (BAT).

L'arqueologia (1 actuació):

- Taller d'arqueologia (CSP i ESO).

Tots els treballs comprenen tres fases. La fase d'activitats prèvies, per a l'assoliment de conceptes clau que s'utilitzaran en el procés; la fase de camp, que es durà a terme durant la visita al monument $o$ al museu, i la fase final, realitzada al mateix Camp o a la classe, per contrastar i avaluar la seqüència didàctica que s'ha realitzat.
Una cosa és l'oferta de treball i l'altra les estratègies. Aquestes són les variables bàsiques de l'observació directa; la combinació de l'observació directa amb la indirecta, utilitzant fonts primàries i secundàries, i les interpretacions simbòliques. Aquestes estratègies s'encaixen en l'ús d'altres fonts. Així, es fan servir les fonts orals (contes, endevinalles, cançons, poemes i entrevistes) i treballs sensorials (escoltar música, percebre sensacions, olorar perfums i productes, reconèixer textures de materials 0 identificar sabors i distingir objectes). Altres recursos emprats per assolir les estratègies són la lectura de maquetes (per treballar una anàlisi deductiva i l'observació directa); la reconstrucció històrica dels materials; la identificació d'imatges, objectes i personatges; la relació de textos amb imatges; la classificació d'ill-lustracions, objectes i productes; la contextualització de restes i edificis; els retallables, etc.

Si aquestes són les estratègies, totes tenen el suport de materials. A part del material bàsic com és el paper, utilitzat sobretot per als quaderns de treball, hi ha altres materials que donen consistència a la proposta. Entre

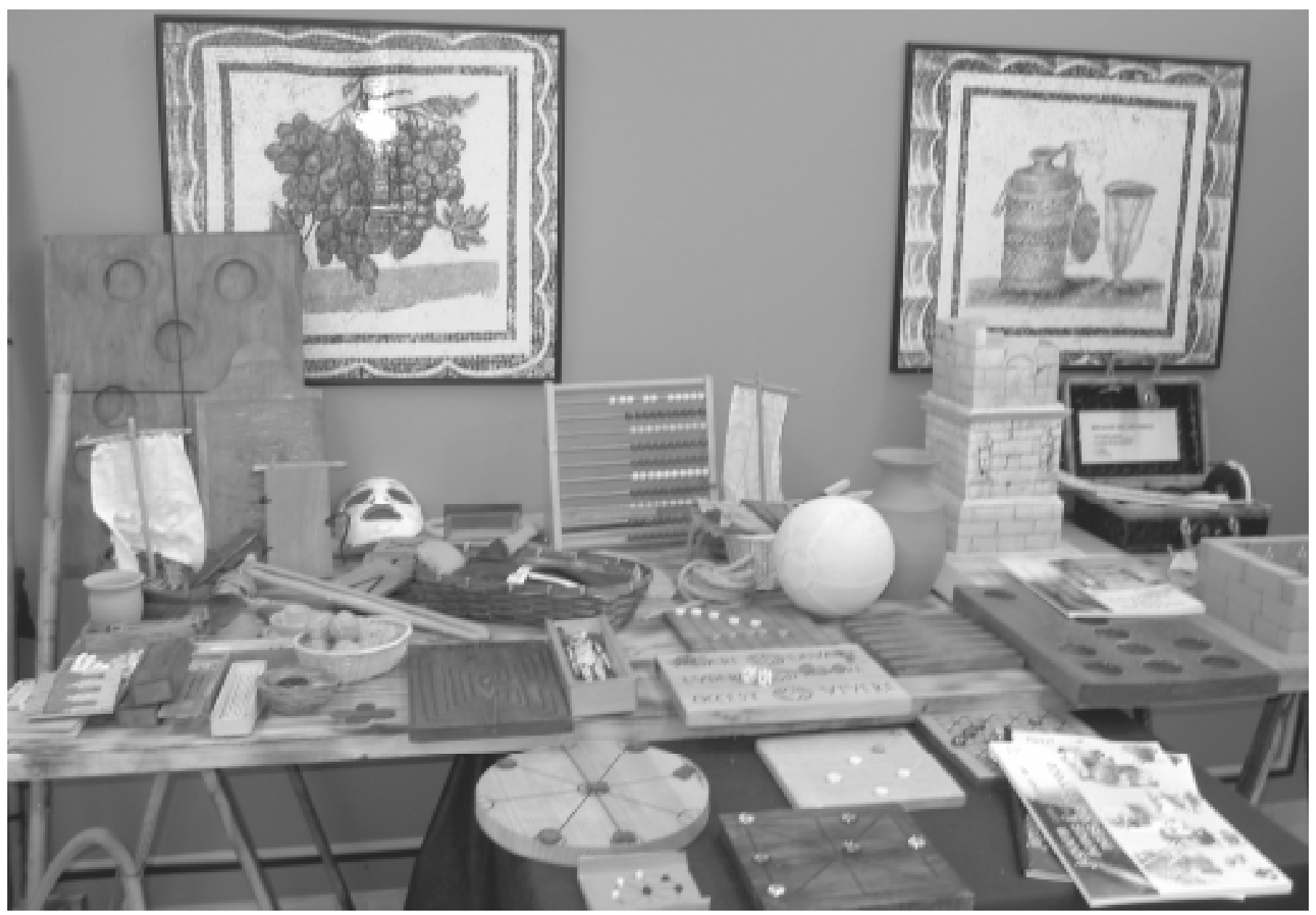




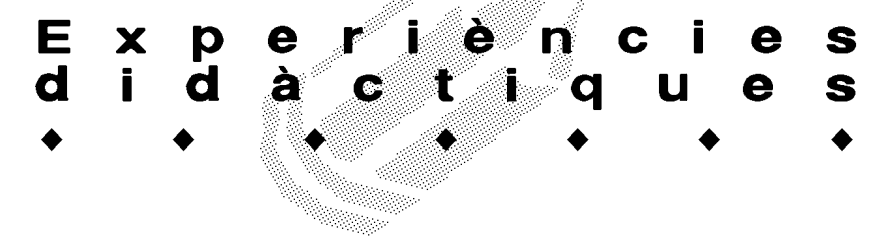

aquests cal esmentar, succintament, el cartró ploma (per als suports), la maqueta d'exposició (en els franel-logrames i les carpetes), la ceràmica (en les maquetes per a invidents i en les rèpliques d'estris de cuina, de transport, etc.), la fusta (en jocs romans, mobiliari i trencaclosques), els metalls (com a instrumental quirúrgic, armes...), el guix (per a les tessel-les i maquetes), la pell (per a les butlles, les sabates), la roba (per al vestuari, per als contenidors), les fotografies, la pols de marbre, els imants i el vidre (en recipients com ara ungüentaris, etc.).

Evidentment, però, una cosa és la teoria, el disseny, la metodologia, els materials, etc., i l'altra la pràctica real amb alumnes. Vegem com es treballa en dos casos dels ressenyats, sintèticament:

Els petits nens i nenes de Tàrraco romana $(\mathrm{Cl})$

La jornada de camp es divideix en dues parts. La primera es du a terme al matí en una aula d'interpretació històrica que reprodueix diferents aspectes de la vida quotidiana: botigues, un triclini, una termopolia i una cucina. L'aula compta també amb un gran plànol de la ciutat romana $i$ un mosaic, a més de diferents vestits de l'època. La segona part, a la tarda, es realitza al circ i al museu.

La sessió del matí s'inicia amb una explicació introductòria del món romà mitjançant un conte que ofereix una visió general de la ciutat i els principals indrets. Tot seguit es fa la interpretació dels grups socials mitjançant el vestuari. A continuació, els alumnes, dividits en petits grups, treballen per racons fent una primera lectura del plànol de la ciutat amb l'ajut de figures (soldats, gladiadors, cavalls, etc.), i experimentant la vida quotidiana a través de la simulació de compres (alimentació i cosmètica), l'elaboració d'un mosaic i la recreació de la diferenciació social.

A la tarda fan una visita al circ, on simulen carreres de quàdrigues i de bigues, i al museu, on observen i treballen el mosaic de la Medusa i alguns jocs.

\section{Tàrraco, la ciutat romana (CSP)}

En aquesta unitat s'empra com a motivació la notícia, apareguda en un diari, de la troballa d'una nina romana a Tarragona i se suggereix la pregunta: "Com deuria ser la vida de la nena que tenia aquesta nina a Tàrraco?"

A partir d'un treball en grup s'inicia un procés deductiu que permet una visió de la vida quotidiana mitjançant aspectes concrets, com ara la ciutat en els espais públics $i$ privats, els habitatges, els jocs, l'escola, etc. Es busca la relació entre la joguina i l'ús que en podia realitzar.

Així mateix, hem de dir que hi altres vies d'estudi que s'endinsen en l'estudi de la Tàrraco romana. Una perspectiva de treball interessant és la recreació de pensar i ser romà des de Tàrraco en un projecte que s'anomena "Tàrraco Viva”, reflexió que aquí no analitzem, atès que ultrapassa l'àmbit del present treball.

\section{Unes paraules de conclusió}

El projecte del Camp d'Aprenentatge parteix del pressupòsit que busca la participació i el consens dels agents implicats. Pretén que s'hi involucri l'escola, el mestre il'alumne.

El treball, en conjunt, prenent com a centre d'interès Tàrraco, es fonamenta en la metodologia del corrent constructivista de l'aprenentatge. Això implica que es proposi partir d'una metodologia activa basada en l'observació directa i personal de l'indret o monument objecte d'estudi, en l'anàlisi de diferents fonts històriques que permetin extreure dades i que complementin l'acció de recerca i, finalment, en el foment del debat per posar en comú i redactar les conclusions finals.

Creiem que el concepte d'estudi de la ciutat romana com a recurs didàctic que s'ha presentat aporta una dimensió complementària, i fins a cert punt alternativa, a l'ensenyament excessivament formalista de l'ensenyament.

El projecte intenta apropar la realitat de la societat romana a la vida real dels alumnes de tots els nivells educatius, trencant l'escassa flexibilitat del sistema educatiu. Relliga, doncs, la interacció entre l'educació formal, la no formal i la informal.

\section{Bibliografia consultada}

AA.DD. La ciudad: su origen, crecimiento e impacto en el hombre. Selecciones del Scientific American. Edit. Hermann Blume. Madrid. 1976.

BAAR, G. Observa e investiga la ciudad. Edit. Kapelusz. Buenos Aires. 1975.

BRUSA, A. i BRESIL, L. Storia, il mondo, culture, relazioni. Laboratorio I, per l'insegnante. Edit. Scolastiche Bruno Mondadori. Milano. 1994.

CARRETERO. M., POZO, J. I. i ASENSIO, M. (comp.). La enseñanza de las Ciencias Sociales. Edit. Aprendizaje Visor. Madrid. 1989.

DEWEY, J. Democràcia i escola. Eumo Editorial/Diputació de Barcelona. Vic. 1985.

Grupo CRONOS (J. Baigorri, G. Castán, R. Cuesta, M.F. Cuadrado). Enseñar la ciudad. Didáctica de la geografía urbana. Ediciones de la Torre. Madrid. 1987.

GAVALDÀ, A. i VIRGILI, M. J. Cómo revivir las huellas romanas desde Tarragona: perspectivas didácticas para lograrlo. «Aula. Historia Social», 2008 (en premsa).

ORDEIX, L. i SANTACANA, J. El patrimoni artístic i cultural. Edit. Graó. Barcelona. 1993.

PLUCKROSE, H. Enseñanza y aprendizaje de la historia. Edit. Ministerio de Educación y Ciencia-Morata. Madrid. 1993.

TREPAT, C.-A. Procedimientos en historia: un punto de vista didáctico. Edit. ICE de la UAB i Graó editorial. Barcelona. 1995. 